\title{
Disposition of Mianserin and Cyclizine in UGT2B10-Overexpressing Human Embryonic Kidney 293 Cells: Identification of UGT2B10 as a Novel N-Glucosidation Enzyme and Breast Cancer Resistance Protein as an $\mathbf{N}$-Glucoside Transporter ${ }^{\circledR}$
}

\author{
Danyi Lu, ${ }^{1}$ Dong Dong, ${ }^{1}$ Qian Xie, Zhijie Li, and Baojian Wu
}

Research Center for Biopharmaceutics and Pharmacokinetics, College of Pharmacy (D.L., Q.X., B.W.), Guangdong Province Key Laboratory of Pharmacodynamic Constituents of TCM and New Drugs Research (D.L., B.W.), and International Ocular Surface

Research Centre and Institute of Ophthalmology, School of Medicine (D.D., Z.L.), Jinan University, Guangzhou, China; and Shenzhen Key Laboratory for Molecular Biology of Neural Development, Shenzhen Institutes of Advanced Technology, Chinese Academy of Sciences, Shenzhen, China (D.L.)

Received February 4, 2018; accepted April 17, 2018

\section{ABSTRACT}

UDP-glucuronosyltransferases (UGTs) play an important role in the metabolism and detoxification of amine-containing chemicals; however, the disposition mechanisms for amines via UGT metabolism are not fully clear. We aimed to investigate a potential role of UGT2B10 in $\mathrm{N}$-glucosidation and to determine the transporters for the excretion of $\mathrm{N}$-glucosides. We first established a human embryonic kidney cell line 293 (HEK293) that stably overexpressed UGT2B10. Incubation of mianserin or cyclizine with the cells generated one $\mathrm{N}$-glucuronide and one $\mathrm{N}$-glucoside. Chemical inhibition (using specific chemical inhibitor Ko143) and biologic inhibition [using specific short hairpin RNA of breast cancer resistance protein (BCRP)] resulted in a significant reduction in efflux of $\mathrm{N}$-glucuronide. Similar results were observed when multidrug resistance-associated protein (MRP4) was inhibited. Furthermore, inhibition of BCRP led to increased intracellular $\mathrm{N}$-glucoside, whereas inhibition of MRP4 caused no changes in disposition of $\mathrm{N}$-glucoside. Overall, the data indicated that BCRP, not MRP4, was responsible for the excretion of $\mathrm{N}$-glucosides, whereas both BCRP and MRP4 contributed to excretion of $\mathrm{N}$-glucuronides. Interestingly, downregulation of $\mathrm{N}$-glucuronidation led to increased $\mathrm{N}$-glucosidation in the cells, supporting the glucosidation as a potential complementary pathway for conventional glucuronidation. In conclusion, UGT2B10 was for the first time identified as an N-glucosidation enzyme. Generated N-glucosides were excreted primarily by the BCRP transporter.

\section{Introduction}

UDP-glucuronosyltransferases (UGTs) are a family of phase 2 drug-metabolizing enzymes best known to catalyze the glucuronidation reaction (UDP-glucuronic acid as the cofactor). Since the product (glucuronide) is hydrophilic and more readily excretable, glucuronidation is generally regarded as a detoxification process (Rowland et al., 2013). Human UGTs are categorized into five subfamilies, namely, UGT1A, 2A, 2B, 3A, and 8A (Rowland et al., 2013). The enzymes from subfamilies UGT1A (nine members) and 2B (seven members) are the main contributors to drug and chemical glucuronidation (Wu et al., 2011). The most prevalent site for glucuronidation (i.e., the position for addition of the glucuronic acid group) is the-OH group (e.g., phenolic hydroxyl, alcoholic hydroxyl or carboxyl). Accordingly, this type of glucuronidation is

This work was supported by the National Natural Science Foundation of China [Grants 81722049, 81573488, and 81503341] and the China Postdoctoral Science Foundation [Grant 2017M622835].

${ }^{1}$ D.L. and D.D. contributed equally to this work

https://doi.org/10.1124/dmd.118.080804.

S This article has supplemental material available at dmd.aspetjournals.org. termed O-glucuronidation. Most UGT enzymes are capable of catalyzing O-glucuronidation (Wu et al., 2011). O-glucuronidation is believed to proceed by using a serine hydrolase-like mechanism wherein the "histidine-aspartate" dyad deprotonates the -OH group and facilitates the conjugation reaction (Radominska-Pandya et al., 2010).

Another common type of glucuronidation occurs at the amine groups and is termed $N$-glucuronidation (Kaivosaari et al., 2011). N-glucuronidation, primarily catalyzed by the two enzymes UGT1A4 and 2B10, plays an important role in the metabolism and detoxification of various drugs containing the amine groups (particularly tertiary amines, e.g., the tricyclic antidepressants amitriptyline and imipramine) (Zhou et al., 2010; Kanoh et al., 2011; Lu et al., 2017b). Although the reaction mechanism for $\mathrm{N}$-glucuronidation is not fully clear, it should differ from that for O-glucuronidation. This is because UGT1A4 and 2B10 lack the catalytic residue histidine. Although the catalytic histidine is necessary (nucleophile activation) for O-glucuronidation to occur, it is not required in N-glucuronidation reactions (Patana et al., 2008; Kerdpin et al., 2009); however, the N-nucleophiles appear to develop a formal positive charge during the substitution reaction, requiring a negatively charged (i.e., aspartic acid) residue to stabilize the transition state (Patana et al., 2008; Kerdpin et al., 2009).

ABBREVIATIONS: BCRP, breast cancer resistance protein; $C L_{\text {int }}$, intrinsic clearance; DMSO, dimethylsulfoxide; GUSB, $\beta$-glucuronidase; HBSS, Hanks' balanced salt solution; HEK293, human embryonic cell line 293; MRP, multidrug resistance-associated protein; MS, mass spectroscopy; NMR, nuclear magnetic resonance; qPCR, quantitative polymerase chain reaction; shRNA, short hairpin RNA; UDPGA, UDP-glucuronic acid; UDPglc, UDP glucose; UGT, UDP-glucuronosyltransferases; UPLC, ultraperformance liquid chromatography. 
There is accumulating evidence that UGT enzymes also catalyze the glucosidation reaction in mammals (Meech et al., 2012). In the glucosidation reaction, UDP-glucose is used as the cofactor instead of UDP-glucuronic acid. Both cofactors are available in mammalian cells for drug conjugation (Chau et al., 2014). Many drug molecules (e.g., morphine, phenobarbital, ibuprofen) and endogenous compounds (e.g., bilirubin, hyodeoxycholic acid) have been reported to undergo both glucuronidation and glucosidation (Fevery et al., 1977; Neighbors and Soine, 1995; Mackenzie et al., 2003; Buchheit et al., 2011; Chau et al., 2014). Furthermore, the human UGT2B7 enzyme has been identified as a main contributor to O-glucosidation (Mackenzie et al., 2003; Buchheit et al., 2011; Chau et al., 2014); however, the UGT isozymes responsible for N-glucosidation remain unknown.

Various studies have been devoted to investigating the glucuronidation pathway in vivo (Xu et al., 2009; Yang et al., 2012; Quan et al., 2015). In addition to the UGT enzymes, efflux transporters [e.g., MRP and breast cancer resistance protein (BCRP)] play a critical role in determining the pharmacokinetics of drugs undergoing glucuronidation (Xu et al., 2009; Yang et al., 2012; Quan et al., 2015). Efflux transporters participate in drug disposition by pumping the glucuronide metabolite (too hydrophilic to diffuse across the membranes) out of cells (Adachi et al., 2005; Sesink et al., 2005). Failed or inefficient glucuronide excretion has a negative effect on overall cellular metabolism, leading to greater exposure of the parent drug (Wang et al., 2016). This is because intracellular metabolite accumulation favors the deglucuronidation reaction (mediated by $\beta$-glucuronidase) that convert the metabolite back to the parent drug (a phenomenon also termed futile recycling) (Sun et al., 2015b; Zhao et al., 2016). Compared with glucuronidation, drug disposition via the glucosidation pathway is poorly characterized. Little is known about the transporters for excretion of $\mathrm{N}$-glucosides.

The disposition mechanisms for amines via UGT metabolism have not been fully established. The objectives of the present study were to investigate a potential role of UGT2B10 in N-glucosidation and to determine the transporters for excretion of $\mathrm{N}$-glucosides. Toward these goals, we first established a cell line stably overexpressing UGT2B10 enzyme. Disposition of mianserin and cyclizine at a cellular level was characterized using the engineered cells. The glucosidation activities of UGTs were determined using an incubation assay supplemented with UDP-glucose. The transporters for conjugate excretion were elucidated by using both chemical and biologic inhibition methods. We demonstrated for the first time that UGT2B10 was an N-glucosidation enzyme and that BCRP was responsible for excretion of $\mathrm{N}$-glucosides.

\section{Materials and Methods}

\section{Materials}

The pLVX-PGK-Puro vector was obtained from BioWit Technologies (Shenzhen, China). Pooled human liver microsomes (HLMs, $n=50$ ), UGT1A1, UGT1A3, UGT1A4, UGT1A6, UGT1A7, UGT1A8, UGT1A9, UGT1A10, UGT2B4, UGT2B7, UGT2B15, and UGT2B17 were purchased from BD Biosciences (Woburn, MA). Alamethicin, amitriptyline, UDP-glucuronic acid (UDPGA), hecogenin, and UDP-glucose (UDP-glc) were purchased from Sigma-Aldrich (St Louis, MO). Amitriptyline $\mathrm{N}$-glucuronide and mianserin $\mathrm{N}$-glucuronide were purchased from Toronto Research Chemicals (North York, ON, Canada). Cyclizine N-glucuronide was obtained from Haimen Baikang Biomedical Ltd. (Jiangsu, China). Cyclizine and desloratadine were obtained from J\&K Chemical Ltd. (Beijing, China). Formic acid and LC-grade acetonitrile were obtained from Millipore (Billerica, MA). Mianserin was obtained from Aladdin chemicals (Shanghai, China). Rabbit monoclonal GAPDH (ab181602) and UGT2B4 (ab173580) and mouse monoclonal UGT2B10 (ab57685) antibodies were obtained from Abcam (Cambridge, MA).

\section{Synthesis of N-Glucosides}

$\mathrm{N}$-glucosides of mianserin and cyclizine were synthesized according to the method developed by Stachulski and colleagues (Iddon et al., 2009). In brief, the quaternary $\mathrm{N}$-glucosides were generated by direct reaction of a secondary
(N-demethyl) amine with glucose or 6-O-trityl glucose, followed by protection and quaternization. Their chemical structures were verified by nuclear magnetic resonance (NMR) analyses.

Mianserin N-Glucoside. ${ }^{1} \mathrm{H}-\mathrm{NMR}[400 \mathrm{MHz}$, dimethylsulfoxide (DMSO)$\left.\mathrm{d}^{6}\right): \delta 7.34-7.08(\mathrm{~m}, 6 \mathrm{H}), 6.70-6.65(\mathrm{~m}, 2 \mathrm{H}), 5.76(\mathrm{~d}, J=5.8 \mathrm{~Hz}, 1 \mathrm{H}), 4.504 .34$ (m, 2H), 4.3 (brs, 4H), 3.86-3.34 (m, 13H), 3.28 (s, 3H) ppm. ${ }^{13} \mathrm{C}-\mathrm{NMR}$ $\left(100 \mathrm{MHz}, \mathrm{DMSO}-\mathrm{d}^{6}\right): \delta 148.8,140.4,138.2,137.6,132.6,127.8,127.6,127.5$, $127.4,126.6,126.5,122.4,119.6,113.2,82.6,73.5,70.6,66.5,64.2,64.0,61.9$, 45.2, 44.6, 43.8, 38.6.

Cyclizine N-Glucoside. ${ }^{1} \mathrm{H}-\mathrm{NMR}\left(400 \mathrm{MHz}, \mathrm{DMSO}-\mathrm{d}^{6}\right): \delta 7.58-7.23(\mathrm{~m}$, $4 \mathrm{H}), 7.23-7.20(\mathrm{~m}, 6 \mathrm{H}), 5.65(\mathrm{~d}, J=5.4 \mathrm{~Hz}, 1 \mathrm{H}), 5.23(\mathrm{~s}, 1 \mathrm{H}), 4.48$ (brs $4 \mathrm{H})$, $4.50-4.34(\mathrm{~m}, 1 \mathrm{H}), 3.65-3.51(\mathrm{~m}, 5 \mathrm{H}), 3.40(\mathrm{~s}, 3 \mathrm{H}), 3.37(\mathrm{~m}, J=8.4 \mathrm{~Hz}, 4 \mathrm{H}), 2.54$ (t, $J=8.4 \mathrm{~Hz}, 4 \mathrm{H}) \mathrm{ppm} .{ }^{13} \mathrm{C}-\mathrm{NMR}\left(100 \mathrm{MHz}, \mathrm{DMSO}-\mathrm{d}^{6}\right): \delta 142.8(2 \mathrm{C}), 132.0$, 130.3 (4C), 128.4 (4C), 125.9 (2C), 113.2, 83.3, 83.0, 76.4, 71.2, 62.3, 61.8, 46.8 (2C), 44.5 (2C), 44.2 .

\section{Construction of HEK293 Cells Overexpressing UGT2B10 (HEK2B10 Cells)}

Human UGT2B10 cDNA was synthesized and subcloned into the XhoI and MluI sites of the pLVX-PGK-Puro vector. The recombinant vector was stably transfected into HEK293T cells according to the previously described procedures (Li et al., 2015; Quan et al., 2015; Sun et al., 2015a). The expressions of UGT2B 10 at mRNA and protein levels in HEK2B10 cells were determined using the methods [quantitative polymerase chain reaction (qPCR) and Western blotting] described in our previous publication (Lu et al., 2017a). Cells were incubated with amitriptyline (a specific UGT2B10 substrate) to verify the enzyme activity of UGT2B10 in HEK2B10 cells, and the formation of amitriptyline glucuronide was detected as previously described ( $\mathrm{Lu}$ et al., 2017a,b). The nontransfected cells (HEK293-WT cells) were used as a negative control.

\section{Short Hairpin RNA-Mediated Silencing of BCRP and MRP4}

We have previously characterized the efflux transporters (BCRP and MRPs) in HEK293 cells (Sun et al., 2015a). The mRNAs of BCRP and three MRP transporters (MRP1, MRP4, and MRP5) were expressed in HEK293 cells (Sun et al., 2015a); however, only BCRP and MRP4 proteins were found in the cells (Sun et al., 2015a). Our previous study also revealed that overexpression of a drug-metabolizing enzyme in HEK293 cells did not alter the expression profile of efflux transporters (Sun et al., 2015a). Thus, previously established short hairpin RNA (shRNA)_BCRP and shRNA_MRP4 plasmids were transiently transfected into HEK2B10 cells following the procedures as described (Quan et al., 2015). Western blotting was used to validate their effectiveness in reducing the expression of BCRP or MRP4 protein as described previously (Quan et al., 2015; Sun et al., 2015a). Forty-eight hours after transfection, cells were used for metabolite excretion experiments.

\section{Metabolite Excretion Experiments}

Metabolite excretion experiments were performed as described previously (Quan et al., 2015; Sun et al., 2015a). In brief, cells were incubated with $2 \mathrm{ml}$ of Hanks' balanced salt solution (HBSS) containing 5 or $20 \mu \mathrm{M}$ substrate (mianserin or cyclizine). To determine the role of efflux transporters, MK-571 $(5 \mu \mathrm{M})$ or Ko143 $(10 \mu \mathrm{M})$ was included in HBSS solution to selectively inhibit the activity of MRP or BCRP. MK-571 and Ko143 were dissolved in DMSO to make their respective stork solutions. At each time point (30,60, 90, and 120 minutes), an aliquot of incubation solution $(200 \mu \mathrm{l})$ was withdrawn and immediately replenished with the same volume of fresh drug-containing HBSS solution. The withdrawal solution was mixed well with acetonitrile $(100 \mu \mathrm{l})$. After the last sampling point, cells were collected and disrupted to determine intracellular accumulation of metabolites as described (Quan et al., 2015). After centrifugation $(15,000 \mathrm{~g}, 10$ minutes), the samples were subjected to ultraperformance liquid chromatography (UPLC)-quadrupole time-of-flight/mass spectroscopy (MS) analyses for determination of conjugated metabolites (both glucuronide and glucoside) of mianserin and cyclizine. The excretion rate of the conjugate and $f_{\text {met }}$ value of glucuronidation/glucosidation in HEK2B10 cells were calculated as previously described (Quan et al., 2015; Sun et al., 2015b).

\section{Cell Lysate Preparation}

HEK2B10 cells grown in 10-cm dishes were collected in Tris buffer $(100 \mathrm{mM})$ and lysed by homogenization using a tight-fitting Dounce homogenizer. Cell 
homogenates were centrifuged at $1000 \mathrm{~g}$ for 5 minutes at $4^{\circ} \mathrm{C}$. The supernatant fraction containing the expressed UGT2B10 enzyme was collected and stored at $-80^{\circ} \mathrm{C}$ until use. Total protein concentration in cell lysates was determined using a bicinchoninic acid assay kit (Beyotime, Shanghai, China).

\section{Glucuronidation and Glucosidation Assays}

The glucuronidation and glucosidation assays were performed as described previously with minor modifications (Chau et al., 2014; Lu et al., 2016, 2017b). In brief, the reaction mixture (100- $\mu$ l total volume) contained HLM $(50 \mu \mathrm{g} / \mathrm{ml})$ or recombinant UGT $(50 \mu \mathrm{g} / \mathrm{ml})$ or HEK2B10 cell lysate $(160 \mu \mathrm{g} / \mathrm{ml}), \mathrm{MgCl}_{2}$ $(4 \mathrm{mM})$, alamethicin $(20 \mu \mathrm{g} / \mathrm{ml})$, and mianserin or cyclizine in $100 \mathrm{mM}$ Tris- $\mathrm{HCl}$ buffer ( $\mathrm{pH}$ 7.4). After preincubation at $37^{\circ} \mathrm{C}$ for 5 minutes, the reaction was initiated by the addition of $8 \mathrm{mM}$ UDPGA (for glucuronidation assay) or UDP-glc (for glucosidation assay), and the incubation was continued for another 60 minutes. The specific UGT inhibitor (desloratadine or hecogenin) or transporter inhibitor (MK-571 or Ko143), whenever applied, was included in the incubation mixture to examine their influences on the glucuronidation/glucosidation activities of mianserin and cyclizine. The reaction was terminated by adding $100 \mu \mathrm{l}$ of ice-cold acetonitrile. After vortexing, the incubation mixture was centrifuged at $15,000 \mathrm{~g}$ for 10 minutes. The supernatant was collected and subjected to UPLC- quadrupole time-of-flight/MS analysis. Preliminary experiments were performed to ensure that the rates of glucuronidation/glucosidation were determined under linear conditions with respect to incubation time (Supplemental Fig. 1) and protein concentration (Supplemental Fig. 2). To characterize the kinetics of glucuronidation and glucosidation reactions, various concentrations of two amines $(0.78-100 \mu \mathrm{M})$ were incubated with HLMs or expressed UGT2B10 enzyme in the presence of an equal amount of two UDP donors (UDPGA and UDP-glc) as described. Kinetic parameters $\left[K_{\mathrm{m}}, V_{\max }\right.$, and intrinsic clearance $\left.\left(C L_{\text {int }}\right)\right]$ for $\mathrm{N}$-glucuronidation/glucosidation of each amine were generated by using the Michaelis-Menten model as described previously ( $\mathrm{Lu}$ et al., 2016).

\section{Quantification of Glucuronides and Glucosides}

Chromatographic separation was performed using the ACQUITY UPLC system (Waters, Milford, MA) equipped with a Luna Omega Polar C18 column $\left(2.1 \times 100 \mathrm{~mm}, 1.6 \mu \mathrm{m}\right.$; Phenomenex, Torrance, CA) maintained at $45^{\circ} \mathrm{C}$. The amine drugs and their conjugate metabolites ( $\mathrm{N}$-glucuronides and $\mathrm{N}$-glucosides) were separated using $0.1 \%$ formic acid in water (mobile phase $\mathrm{A}$ ) and acetonitrile containing $0.1 \%$ formic acid (mobile phase B) at a flow rate of $0.35 \mathrm{ml} / \mathrm{min}$. The gradient elution program was as follows: $0-1$ minute, isocratic elution $2 \% \mathrm{~B} ; 1-$ 3 minutes, linear gradient $2 \%-50 \% \mathrm{~B} ; 3-3.3$ minutes, isocratic elution $50 \% \mathrm{~B}$; and 3.3-4 minutes, linear gradient $50 \%-2 \% \mathrm{~B}$. Mass spectrometry was performed on the Waters Xevo G2 Q-TOF mass spectrometer using the electrospray ionization source operated at positive ion mode under the conditions described previously (Lu et al., 2017b). Quantification of mianserin, mianserin $\mathrm{N}$-glucuronide, mianserin $\mathrm{N}$-glucoside, cyclizine, cyclizine $\mathrm{N}$-glucuronide and cyclizine $\mathrm{N}$-glucoside was performed using the exacted ion chromatograms of $\mathrm{m} / \mathrm{z}$ $265.29,441.26,427.29,267.31,443.28$, and $429.30 \mathrm{Da}$, respectively (with a mass window of $\pm 0.05 \mathrm{Da}$ ). The concentrations of glucuronides and glucosides were determined according to the standard curves derived from authentic compounds $(0.005-10 \mu \mathrm{M})$. All analytes were verified to be stable during the analytical period.

\section{Statistical Analysis}

Data are presented as mean \pm S.D. Statistical differences were analyzed by one-way analysis of variance or Student's $t$ test as appropriate, and the level of significance was set at $P<0.05(*)$ or $P<0.01(* *)$ or $P<0.001$ (***). $^{*}$.
A

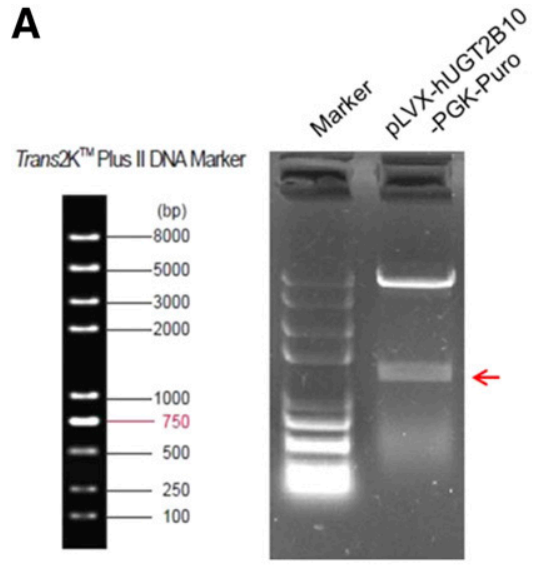

C

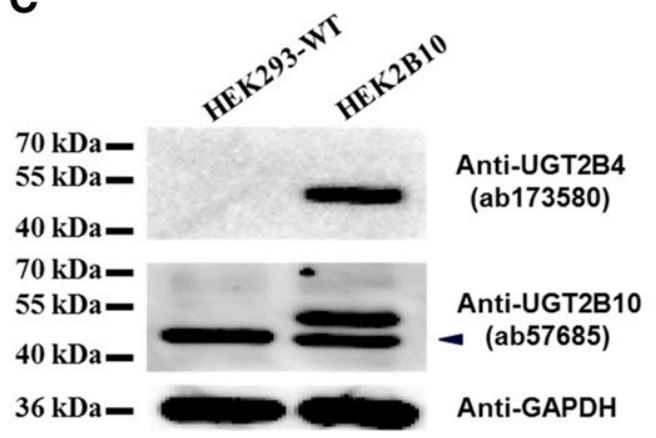

B

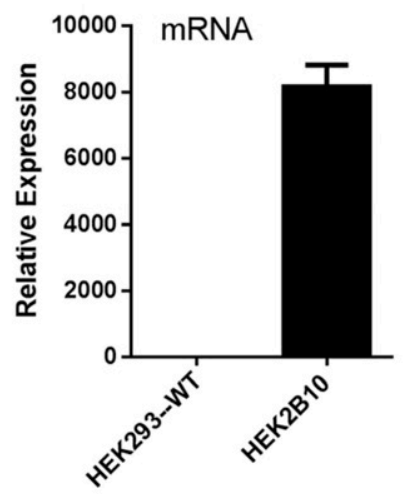

D
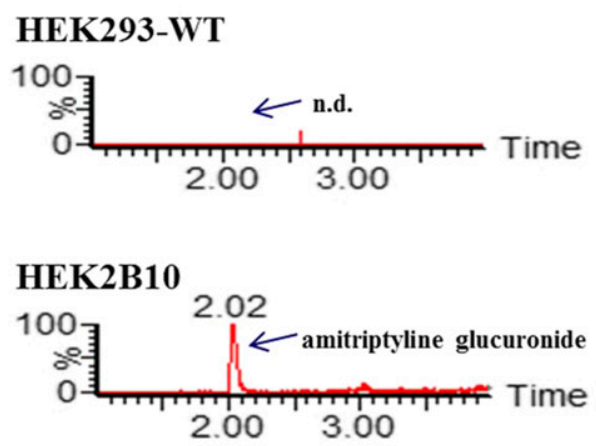

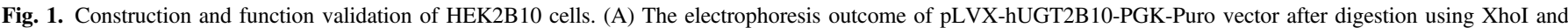

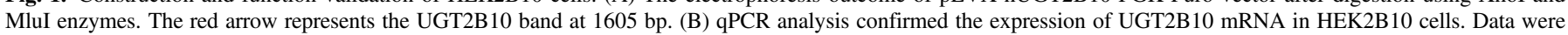

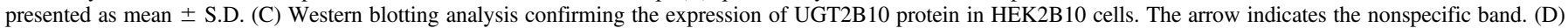
UPLC-MS analysis confirming the N-glucuronidation activity of amitriptyline (a specific UGT2B10 substrate) in HEK2B10 cells. n.d., not detected. 


\section{A}

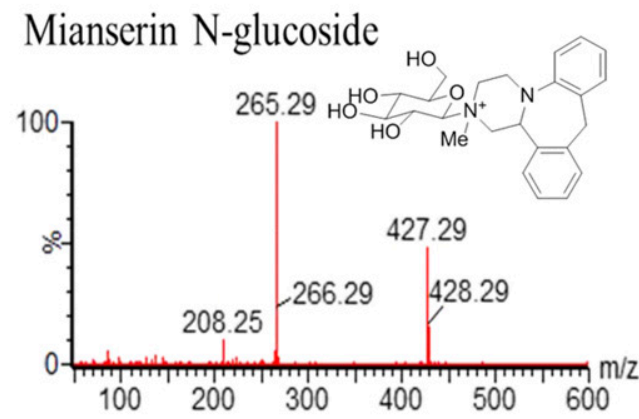

B

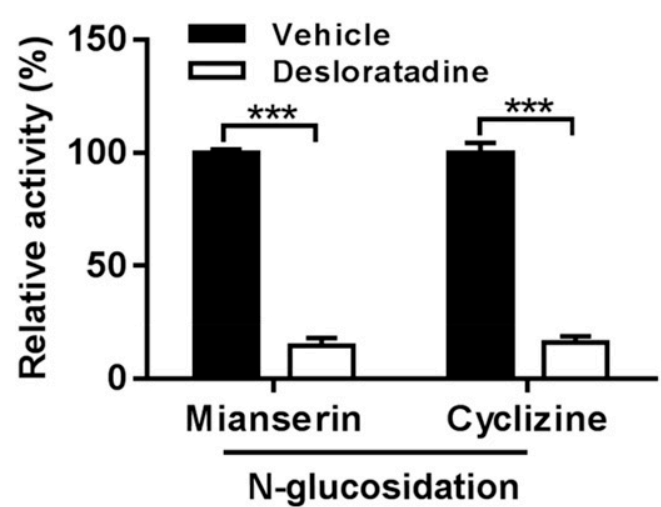

Cyclizine N-glucoside

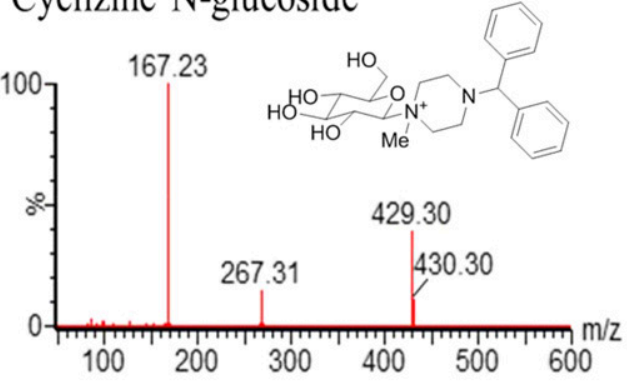

C

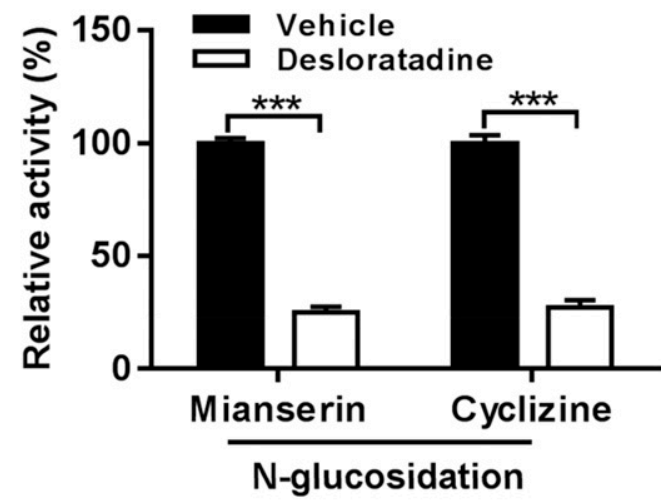

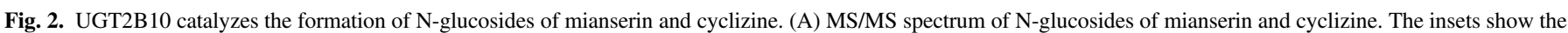

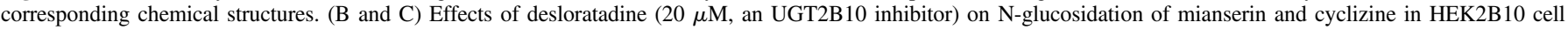
lysates (B) and HLMs (C). Data are presented as mean \pm S.D. $* * * P<0.001$ compared with vehicle control.

\section{Results}

Establishment of UGT2B10-Overexpressing HEK293 Cells (HEK2B10 Cells). UGT2B10 cDNA was subcloned into the XhoI and $M l u \mathrm{I}$ sites of the pLVX-PGK-Puro vector. Digestion of the recombinant pLVX-hUGT2B10-PGK-Puro vector by the restriction enzymes (XhoI and $M l u \mathrm{I}$ ) produced a fragment that corresponded well to the UGT2B10 cDNA (1605 bp) (Fig. 1A). DNA sequencing confirmed that the sequence of UGT2B10 cDNA was identical with the published genomic sequence (NM_001075). The HEK2B10 cells were obtained by puromycin selection after transducing the lentiviral particles (containing the recombinant vector) into the wild-type HEK293 cells (HEK293-WT). The UGT2B10 mRNA was significantly overexpressed in HEK2B10 cells as revealed by qPCR analysis using specific UGT2B10 primers (Fig. 1B). Accordingly, the UGT2B10 protein was detected by commercial UGT2B4 and UGT2B10 antibodies in HEK2B10 cells but not in HEK293-WT cells (Fig. 1C). We previously showed that the commercial UGT2B4 antibody can recognize UGT2B10 protein (Lu et al., 2017a). The commercial UGT2B10 antibody produced a nonspecific band (indicated by an arrow in Fig. 1C) as also noted previously (Lu et al., 2017a). Moreover, amitriptyline N-glucuronide was generated and excreted into the extracellular solution after incubation of amitriptyline (a UGT2B10 probe substrate) with HEK2B10 cells (Fig. 1D). By contrast, no metabolite was found in HEK293-WT cells (Fig. 1D). Taken together, these results indicated that the engineered HEK2B10 cells significantly expressed active UGT2B10 protein.

UGT2B10 Catalyzes Both N-Glucuronidation and N-Glucosidation of Mianserin and Cyclizine in HEK2B10 Cells. Incubation of mianserin or cyclizine with intact HEK2B10 cells generated one $\mathrm{N}$-glucuronide (a mass increase of 176 Da compared with the parent amines). UGT2B10 was responsible for $\mathrm{N}$-glucuronidation of these amines in the engineered cells because the wild-type cells (lacking in expression of UGT2B10) generated no metabolites (Lu et al., 2017b). Surprisingly, another type of metabolite, with an increase of $162 \mathrm{Da}$ in mass and a same retention time as the $\mathrm{N}$-glucuronide, was also found for each of two amines (Fig. 2A). This metabolite was initially proposed to be a demethylation product of the $\mathrm{N}$-glucuronide; however, incubation of each of two amines with HLMs or HEK2B10 cell lysate in the presence of both NADPH and UDPGA did not generate such metabolite. Interestingly, such metabolite was produced when UDP-glc was included in the incubation system, indicating that it was an $\mathrm{N}$-glucoside metabolite. By using synthetic authentic compounds, we confirmed that such metabolite was indeed a quaternary $\mathrm{N}$-glucoside. Formation of the N-glucosides in HEK2B10 cell lysate and HLMs was significantly inhibited by desloratadine (a UGT2B10 inhibitor) (Fig. 2, $\mathrm{B}$ and $\mathrm{C}$ ), suggesting that UGT2B10 catalyzed the N-glucosidation of mianserin and cyclizine in HEK2B10 cells. In addition, reaction phenotyping with UGT1A and 2B enzymes showed UGT2B10 was the only enzyme capable of catalyzing $\mathrm{N}$-glucosidation of the two amines (Fig. 3A). The rates of glucosidation were not altered by hecogenin, a specific inhibitor UGT1A4 (Fig. 3B). Therefore, UGT1A4, the other major N-glucuronidation enzyme, did not catalyze $\mathrm{N}$-glucosidation reactions.

In the presence of UDP-glc and UDPGA, both glucosides and glucuronides were generated from mianserin and cyclizine by HLMs and recombinant UGT2B10 enzyme (Fig. 3C). All reactions obeyed the Michaelis-Menten kinetics (Fig. 3C). Glucuronidation was more 
A

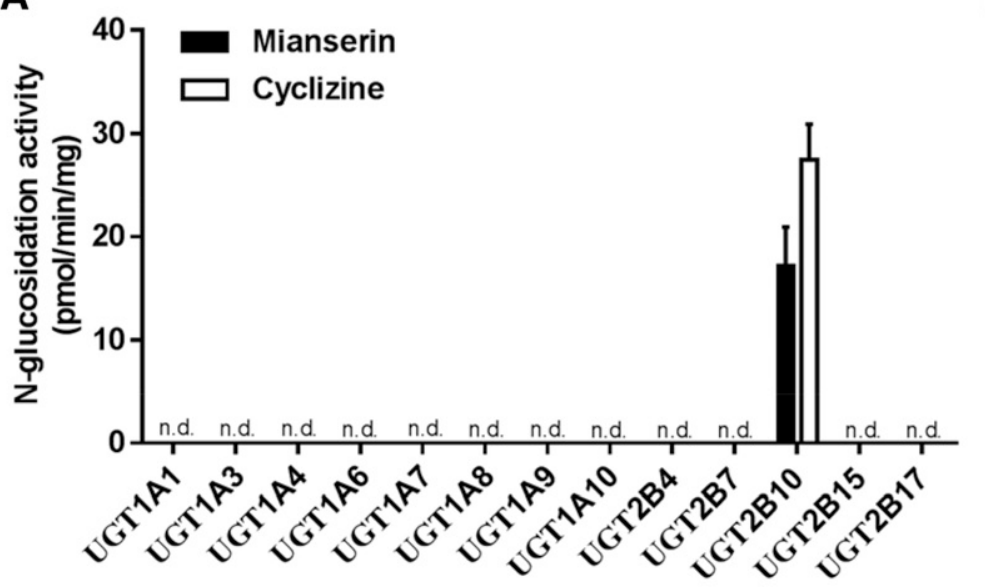

B

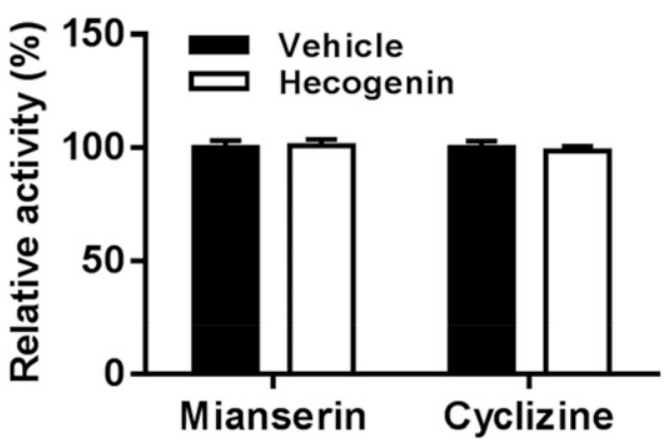

$\mathrm{N}$-glucosidation
C

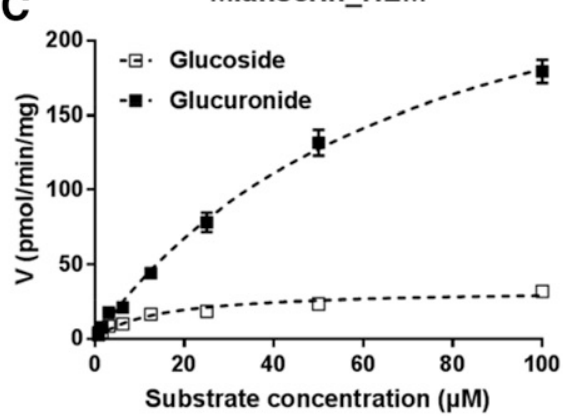

Cyclizine_HLM

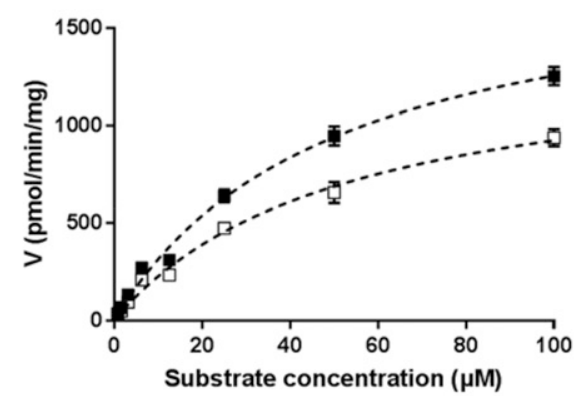

Mianserin_UGT2B10

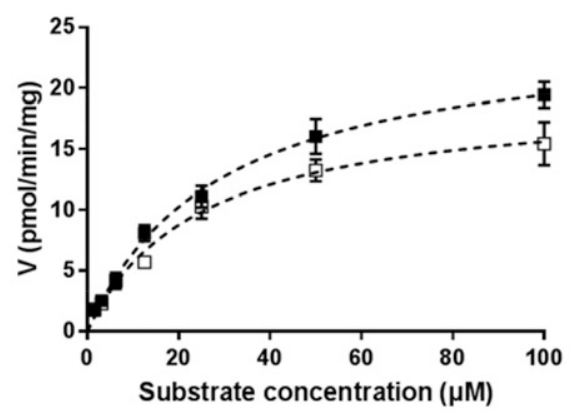

Cyclizine_UGT2B10

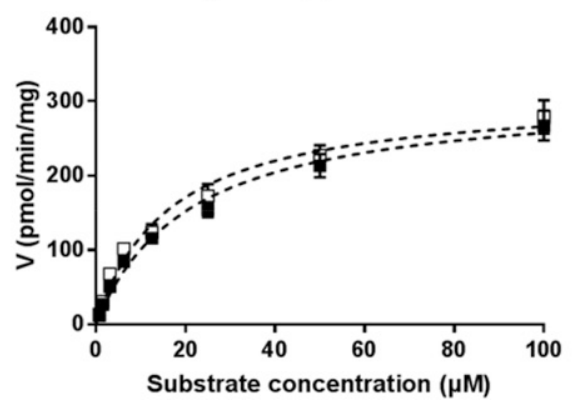

Fig. 3. UGT2B10, not UGT1A4, catalyzes N-glucosidation of mianserin and cyclizine. (A) N-glucosidation of mianserin and cyclizine by 13 recombinant human UGT enzymes. (B) Effects of hecogenin (10 $\mu \mathrm{M}$, an UGT1A4 inhibitor) on the N-glucosidation of mianserin and cyclizine in HLMs. (C) Kinetic analyses of N-glucuronidation and N-glucosidation of mianserin and cyclizine in HLMs and UGT2B10 enzyme supplemented with an equal amount of UDPGA and UDP-glu. Data are presented as mean \pm S.D.

efficient (with higher $V_{\max }$ and $C L_{\text {int }}$ values) than glucosidation for two amines in HLMs (Fig. 3C; Table 1). By contrast, similar kinetics were observed between glucuronidation and glucosidation for mianserin and cyclizine in UGT2B10 enzyme (Fig. 3C; Table 1).

Concentration-Dependent Excretion of N-Glucuronides and N-Glucosides in HEK2B10 Cells. Both N-glucuronide and $\mathrm{N}$-glucoside were efficiently generated and excreted after incubation of each of two amines (mianserin and cyclizine) with HEK2B10 cells. Excretion of each $\mathrm{N}$-glucuronide markedly increased with an increase in the concentration of parent amines (Fig. 4, A-C). The excretion rates at a concentration of $20 \mu \mathrm{M}$ for mianserin $\mathrm{N}$-glucuronide and cyclizine $\mathrm{N}$-glucuronide were 1.13 and $4.89 \mathrm{pmol} / \mathrm{min}$, respectively (Fig. 4C). Likewise, excretion of each $\mathrm{N}$-glucoside significantly increased with an increase in the concentration of parent amines (Fig. 4, D-F). The excretion rates at a concentration of $20 \mu \mathrm{M}$ for mianserin $\mathrm{N}$-glucoside and cyclizine $\mathrm{N}$-glucoside were 0.29 and $1.10 \mathrm{pmol} / \mathrm{min}$, respectively (Fig. 4F).

Effects of Transporter Inhibitors on Excretion of N-Glucuronides and N-Glucosides in HEK2B10 Cells. Nglucuronide excretion was significantly decreased by the MRP inhibitor MK-571 $(5 \mu \mathrm{M})$ and the BCRP inhibitor Ko143 $(10 \mu \mathrm{M})$ (Fig. 5, A and B). Accordingly, the excretion rates of two $\mathrm{N}$-glucuronides were remarkably decreased (Fig. 5C). By contrast, the intracellular levels of $\mathrm{N}$-glucuronides were significantly increased by the transporter inhibitors (Fig. 5D). Furthermore, chemical inhibition of MRP or BCRP led to a decrease in the extent of glucuronidation for each amine (Fig. 5E). The results indicated that the efflux transporters MRP and BCRP were involved in the excretion of $\mathrm{N}$-glucuronides. Also, these efflux transporters could modify cellular N-glucuronidation. 
TABLE 1

Kinetic parameters derived from $\mathrm{N}$-glucuronidation and $\mathrm{N}$-glucosidation of mianserin and cyclizine by HLMs and expressed UGT2B10 enzymes supplemented with an equal amount of two UDP donors (UDP-glc and UDPGA)

Data are represented by mean \pm S.D.

\begin{tabular}{cccccc}
\hline Substrate & Enzyme & Reaction Type & $\begin{array}{c}V_{\max } \\
(\mathrm{pmol} / \mathrm{min} \text { per milligram })\end{array}$ & $\begin{array}{c}K_{\mathrm{m}} \\
(\mu \mathrm{M})\end{array}$ & $\begin{array}{c}C L_{\text {int }} \\
(\mu \mathrm{l} / \mathrm{min} \text { per milligram })\end{array}$ \\
\hline \multirow{5}{*}{ Mianserin } & HLM & Glucosidation & $32.8 \pm 2.76$ & $13.6 \pm 3.49$ & $2.41 \pm 0.65$ \\
& HLM & Glucuronidation & $311 \pm 16.8$ & $72.0 \pm 7.16$ & $4.32 \pm 0.49$ \\
& UGT2B10 & Glucosidation & $19.4 \pm 1.01$ & $24.3 \pm 3.28$ & $0.80 \pm 0.12$ \\
& UGT2B10 & Glucuronidation & $25.1 \pm 0.89$ & $28.9 \pm 2.54$ & $0.87 \pm 0.08$ \\
& HLM & Glucosidation & $1410 \pm 118$ & $52.6 \pm 8.99$ & $26.8 \pm 5.10$ \\
& HLM & Glucuronidation & $1883 \pm 129$ & $50.1 \pm 7.12$ & $37.6 \pm 5.90$ \\
& UGT2B10 & Glucosidation & $310 \pm 18.7$ & $16.4 \pm 2.88$ & $18.9 \pm 3.51$ \\
& UGT2B10 & Glucuronidation & $312 \pm 16.9$ & $21.14 \pm 3.09$ & $14.8 \pm 2.27$ \\
\hline
\end{tabular}

$C L_{\text {int }}$, the intrinsic clearance; $K_{\mathrm{m}}$, the Michaelis constant; $\mathrm{V}_{\max }$, the maximal velocity.

Inhibition of MRP by MK-571 did not show any effects on the formation and excretion of $\mathrm{N}$-glucosides (Fig. 6). By contrast, inhibition of BCRP by Ko143 led to a significant increase in intracellular glucoside levels, as well as a reduction in excretion of two N-glucosides (Fig. 6, A and B). In contrast to reduced total N-glucuronidation, both MK-571 and Ko143 enhanced the total $\mathrm{N}$-glucosidation in HEK2B10 cells (Fig. 6C). Taken together, the results indicated that $\mathrm{BCRP}$ played a dominant role in excretion of $\mathrm{N}$-glucosides, whereas both MRP and BCRP contributed to excretion of N-glucuronides. Furthermore, N-glucosidation represented a complementary metabolic pathway to $\mathrm{N}$-glucuronidation.

Effects of Transporter Inhibitors on N-Glucuronidation and N-Glucosidation Activities. Previous studies have disclosed that transporter inhibitors have the potential to alter the enzymatic activities of phase 2 enzymes (Hu et al., 2003; Barrington et al., 2015; Quan et al., 2015; Sun et al., 2015a). For a better interpretation of inhibition data of metabolite excretion, we examined whether MK-571 and Ko143 would modulate $\mathrm{N}$-glucuronidation and $\mathrm{N}$-glucosidation activities of UGT2B10. MK-571 (5 $\mu \mathrm{M})$ had no influences on N-glucuronidation and N-glucosidation reactions (Fig. 7). Ko143 (10 $\mu \mathrm{M})$ inhibited the $\mathrm{N}$-glucuronidation of mianserin and cyclizine (Fig. 7A), whereas it showed no effects on $\mathrm{N}$-glucosidation reactions (Fig. 7).

Effects of Transporter Knockdown on Excretion of N-Glucuronides and N-Glucosides in HEK2B10 Cells. The shRNA targeting MRP4 or BCRP was transiently introduced into HEK2B10 cells. The knockdown efficiency of transporter protein in HEK2B10 cells was verified to be about $50 \%$, similar to our previous results ( $\mathrm{Li}$ et al., 2015; Sun et al., 2015a). Silencing of MRP4 or BCRP resulted
A

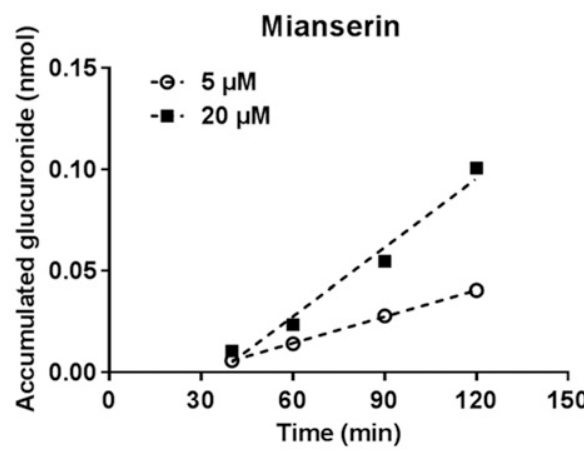

D

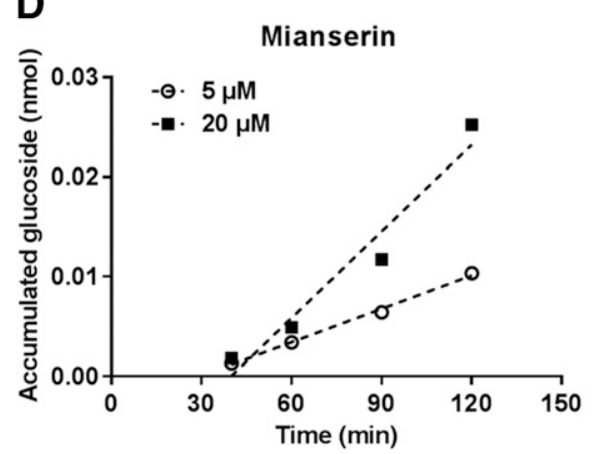

B
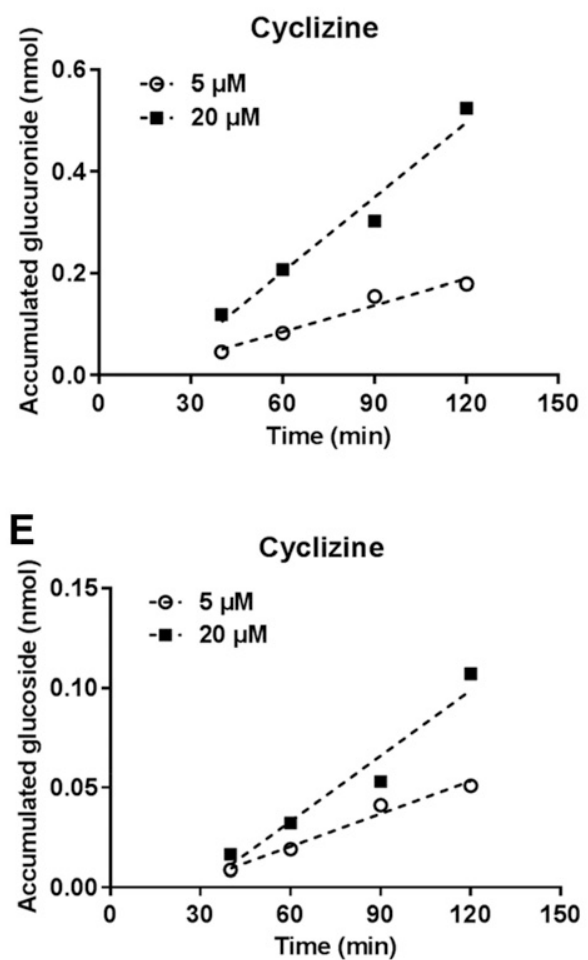

C
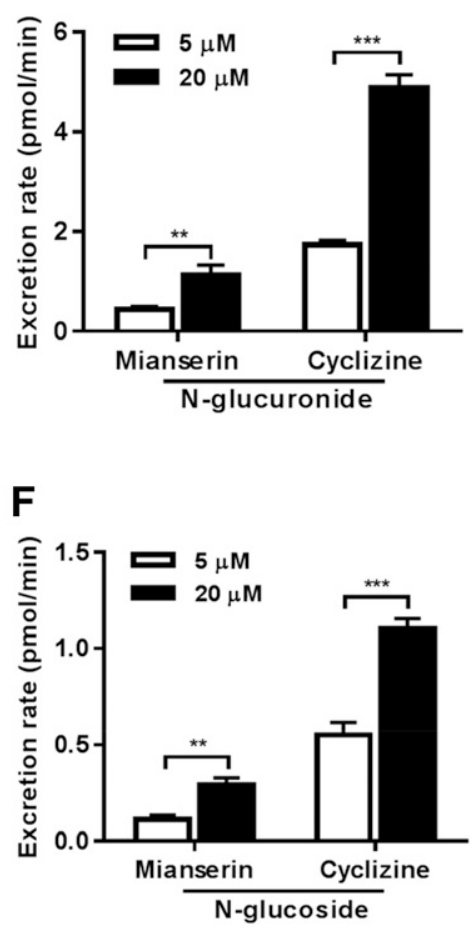

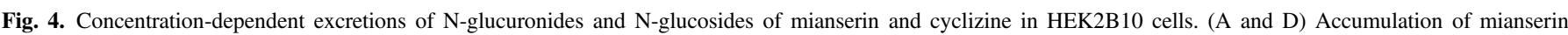

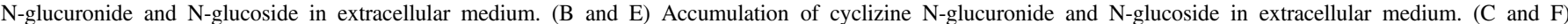

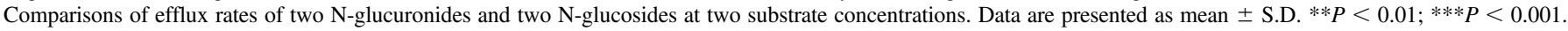




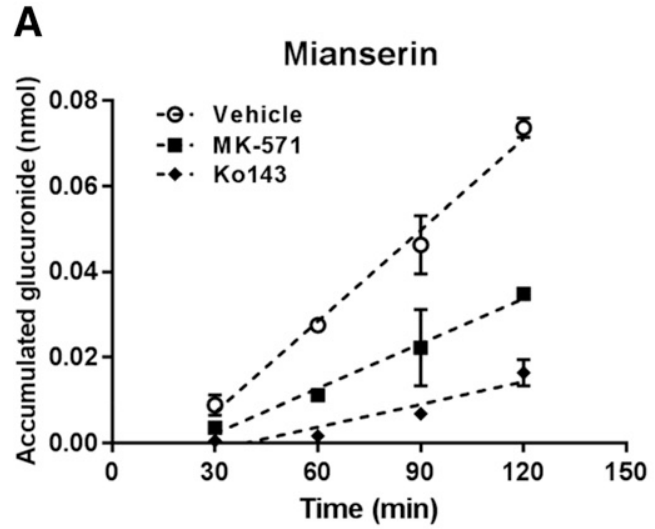

C

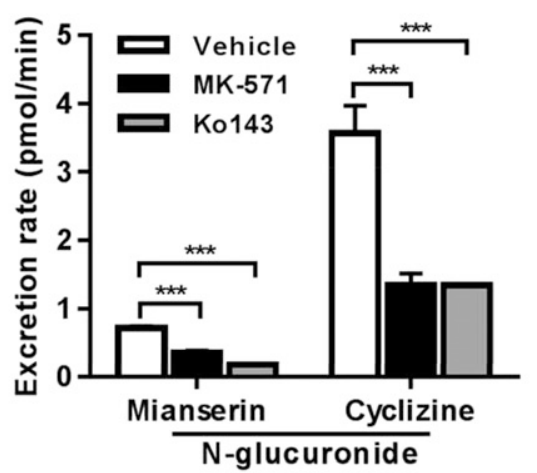

B

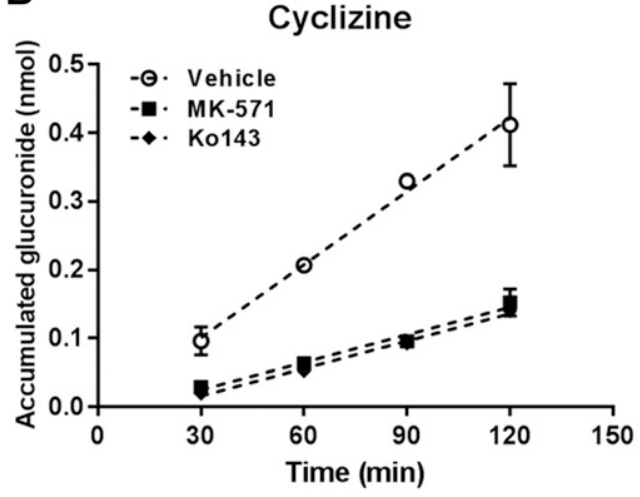

D

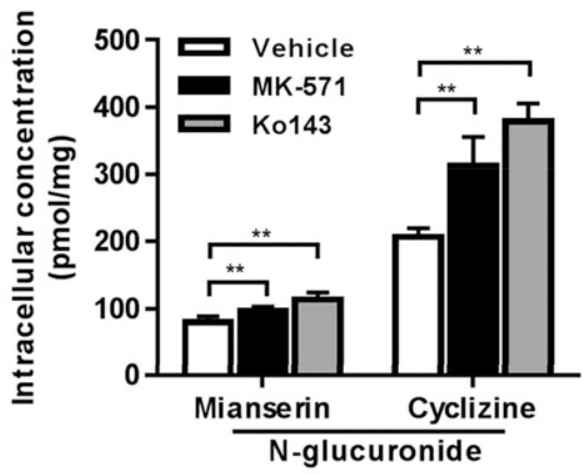

E

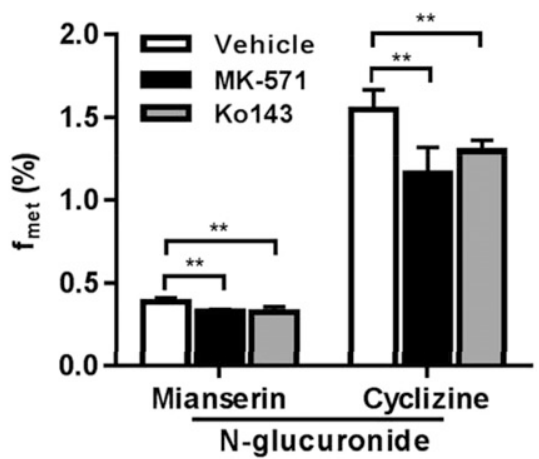

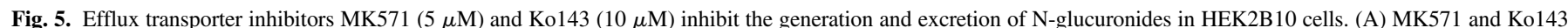

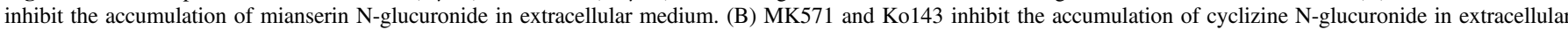

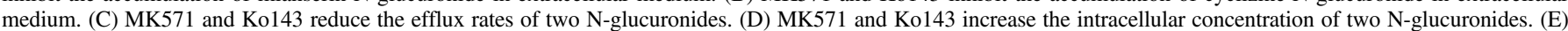

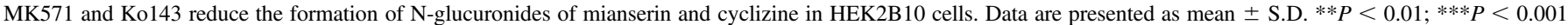
compared with vehicle control.

in an obvious reduction in excretion of two N-glucuronides (Fig. 8A). In addition, the intracellular levels of $\mathrm{N}$-glucuronides were significantly elevated after MRP4 or BCRP silencing (Fig. 8B). Furthermore, knockdown of single transporter led to a moderate decrease in overall cellular N-glucuronidation of two amines (Fig. 8C). The results clearly indicated that MRP4 and BCRP were two important contributors to excretion of $\mathrm{N}$-glucuronides.
MRP4 silencing did not cause any changes in N-glucosidation of mianserin and cyclizine or in excretion of their N-glucosides (Fig. 8, DF). By contrast, BCRP silencing significantly reduced $\mathrm{N}$-glucoside excretion and promoted its intracellular accumulation (Fig. 8, D and E). Interestingly, BCRP silencing resulted in a slight but significant increase in the extent of total cellular $\mathrm{N}$-glucosidation of mianserin and cyclizine (Fig. 8F). Taken together, the results indicated that BCRP, not MRP4,
A

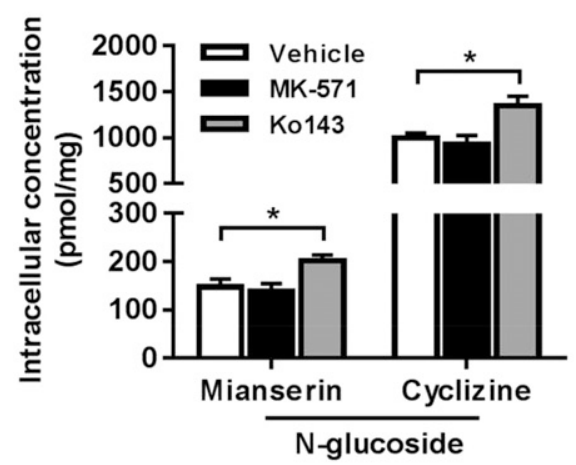

B

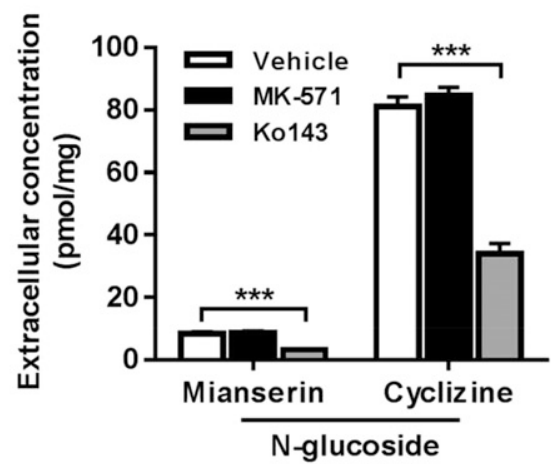

C

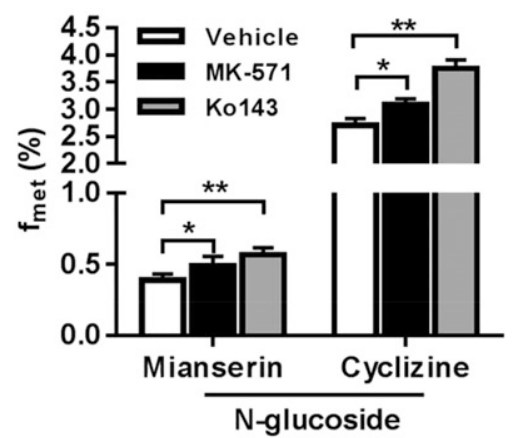

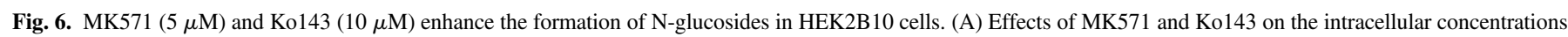

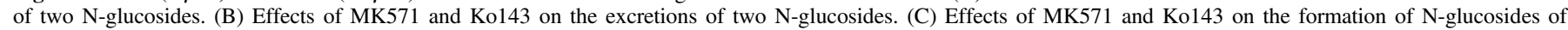
mianserin and cyclizine in HEK2B10 cells. Data are presented as mean \pm S.D. ${ }^{*} P<0.05 ; * * P<0.01 ; * * * P<0.001$ compared with vehicle control. 
A

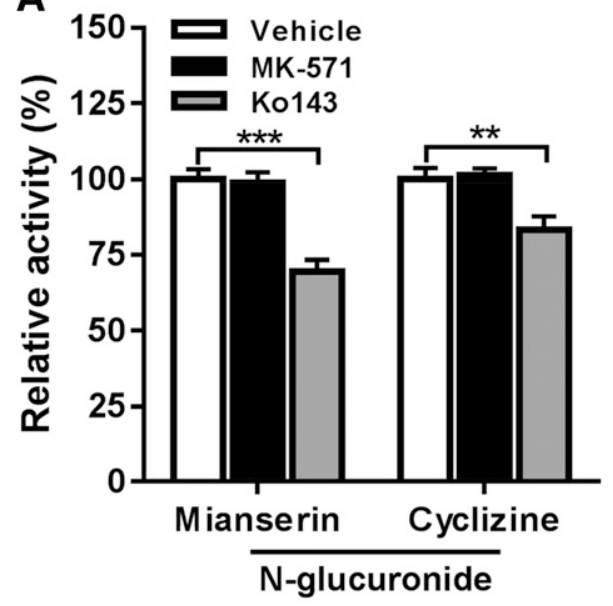

B

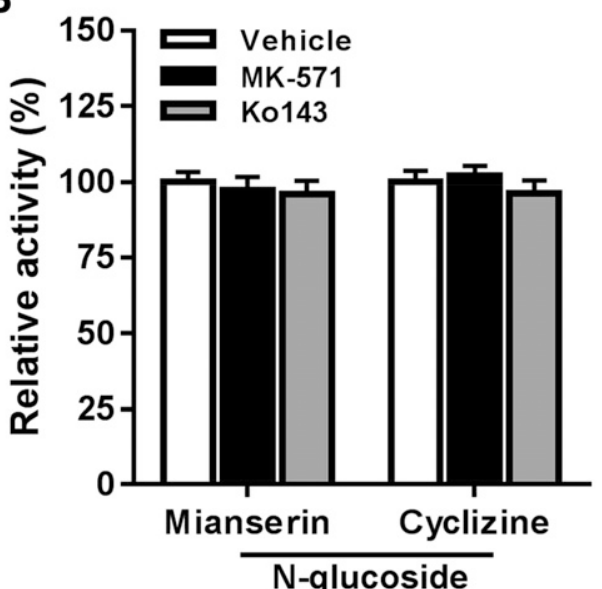

Fig. 7. MK571 and Ko143 show minor effects on UGT2B10 activity. Effects of MK571 and Ko143 on the (A) glucuronidation and (B) glucosidation of mianserin and cyclizine by UGT2B10 enzyme. Data are presented as mean \pm S.D. $* * * P<0.001$ compared with vehicle control. was responsible for excretion of N-glucosides, whereas both BCRP and MRP4 contributed to excretion of N-glucuronides.

\section{Discussion}

In this study, we successfully established a UGT2B10overexpressing HEK293 cell line (named HEK2B10 cells) using lentiviral transfection approach. Disposition of two amines (i.e., mianserin and cyclizine) was characterized using the engineered cells. We demonstrated that UGT2B10 catalyzed both N-glucuronidation and $\mathrm{N}$-glucosidation, generating both $\mathrm{N}$-glucuronides and $\mathrm{N}$-glucosides in HEK2B10 cells (Figs. 2 and 4). The specific role of UGT2B10 in N-glucosidation was confirmed in reaction phenotyping with recombinant UGT enzymes (Fig. 3). Furthermore, we provided strong evidence that $\mathrm{BCRP}$ was primarily responsible for excretion of $\mathrm{N}$-glucosides, whereas both BCRP and MRP4 were actively involved in excretion of $\mathrm{N}$-glucuronides (Figs. 5 and 6). Our study therefore contributed significantly to a deep understanding of the mechanisms for cellular disposition of mianserin and cyclizine via UGT metabolism.

It was a novel finding that UGT2B10 was capable of catalyzing $\mathrm{N}$-glucosidation reactions by using UDP-glucose as the cofactor. Identification of an enzyme for $\mathrm{N}$-glucosidation can well explain the observed N-glucosides in vivo (Neighbors and Soine, 1995). The extent ratio of $\mathrm{N}$-glucuronidation versus $\mathrm{N}$-glucosidation in HEK293 cells appeared to be highly dependent on the substrate structures (Figs. 5 and 6). $\mathrm{N}$-glucosidation is an equally important pathway for mianserin compared with $\mathrm{N}$-glucuronidation. For cyclizine, $\mathrm{N}$-glucosidation is even more efficient than $\mathrm{N}$-glucuronidation (Figs. 5 and 6). Therefore, $\mathrm{N}$-glucosidation may play a significant role in the metabolism of certain amines. It is necessary to characterize this pathway henceforth which possibly had been underestimated in the past.
A

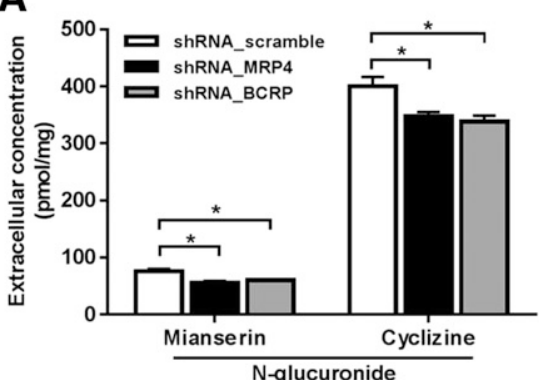

D

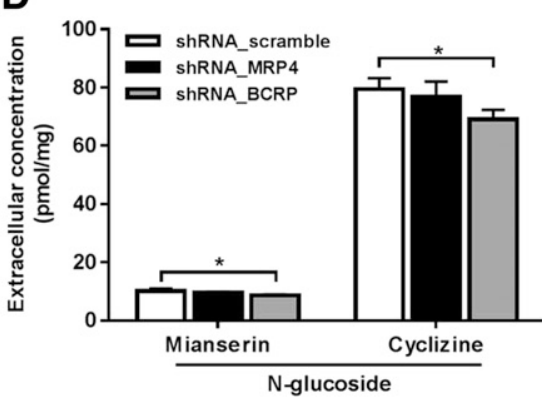

B

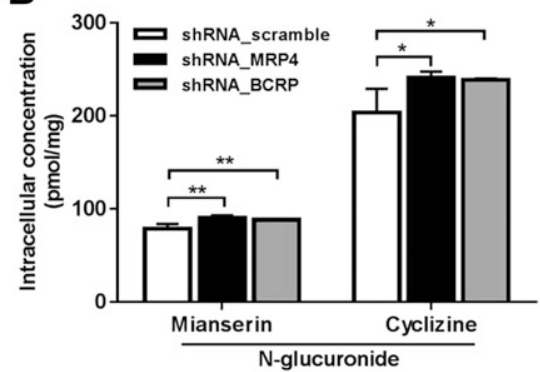

E

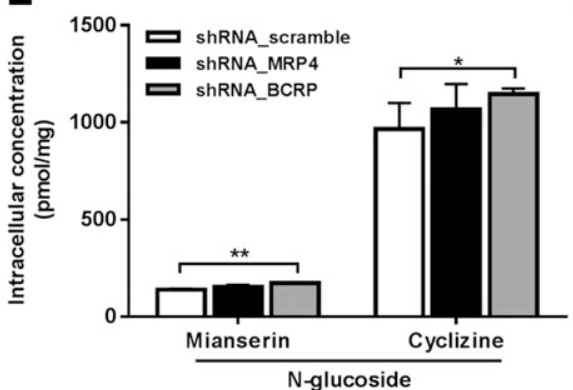

C

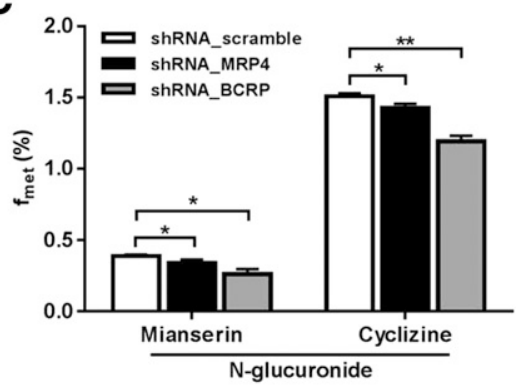

$\mathbf{F}$

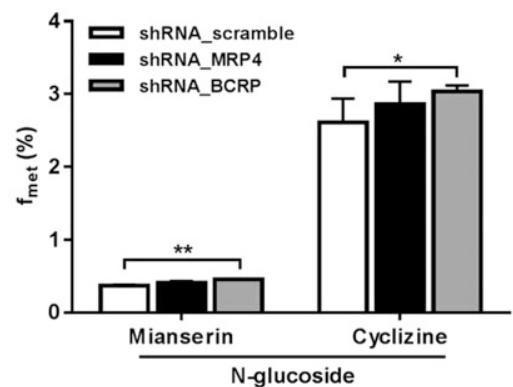

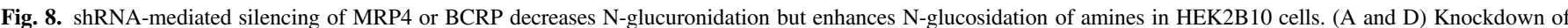

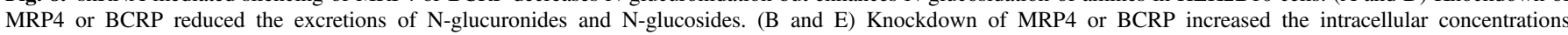

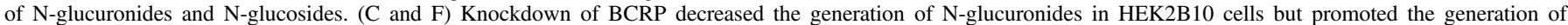
$\mathrm{N}$-glucosides. Data are presented as mean \pm S.D. ${ }^{*} P<0.05 ; * * P<0.01$ compared with scramble-transfected cells. 
A previous study proposed that morphine glucuronidation and glucosidation occur as complementary metabolic pathways because both reactions were mediated by a common enzyme (UGT2B7) (Chau et al., 2014). Consistently, our results lent a strong support to the notion that glucosidation can serve as a compensating pathway for glucuronidation. Inhibition of N-glucuronidation by downregulating metabolite excretion led to increased N-glucosidation in HEK2B10 cells (Figs. 6 and 8). Mechanically, enhancement of $\mathrm{N}$-glucosidation in the cells was due to elevated exposure of parent drug caused by decreased $\mathrm{N}$-glucuronidation. This novel reaction compensation mechanism manifested the versatility of UGT enzymes in chemical detoxification. It was noteworthy that shRNA_MRP4 decreases the N-glucuronidation but fails to enhance $\mathrm{N}$-glucosidation (Fig. 8). This was probably because the extent of N-glucuronidation reduction caused by shRNA_MRP4 was somewhat limited $(<10 \%)$ and unable to cause a significant change in $\mathrm{N}$-glucosidation.

We show for the first time that UGT2B10 metabolizes mianserin and cyclizine using UDP-glucose; however, it was not the first demonstration that UGT enzymes can use other types of UDP-sugars other than UDP-glucuronic acid (as the cofactor) to conjugate chemicals. For instance, UGT2B7 and UGT3A2 use UDP-glucose to glucosidate a broad range of both xenobiotics and endobiotics (Mackenzie et al., 2003, 2011; Buchheit et al., 2011; Chau et al., 2014). UGT3A1 specifically catalyzes the transfer of $\mathrm{N}$-acetylglucosamine from UDP-Nacetylglucosamine to various compounds such as ursodeoxycholic acid (Mackenzie et al., 2008). UGT8 exclusively uses UDP-galactose to galactosidate ceramide and bile acids (Meech et al., 2015). The discovery of significant glucosidation activities of UGT2B7 and 2B10, two important drug glucuronidation enzymes, should change our traditional view that UGT enzymes are purely glucuronidation enzymes for drug detoxification (Chau et al., 2014).

It was noteworthy that inhibition of efflux transporter activities led to reduced total $\mathrm{N}$-glucuronidation in the cells (Fig. 5), a phenomenon previously termed glucuronidation-transport interplay (Zhang et al., 2015). This was not surprising because glucuronide efflux is closely linked to cellular glucuronidation through the deglucuronidation reaction (i.e., the conversion of metabolite back to the parent drug) (Wang et al., 2016). Inhibition of glucuronide efflux certainly results in accumulation of intracellular glucuronide that favors the deglucuronidation, thereby reducing total metabolism (Wang et al., 2016). The deglucuronidation for O-glucuronides has been reported to be catalyzed by $\beta$-glucuronidase (GUSB) (Sun et al., 2015b). It was reported that $\mathrm{N}$-glucuronides could be hydrolyzed by GUSB from animals and/or Escherichia coli (Kowalczyk et al., 2000; Mastrianni et al., 2016). Whether GUSB is involved in deglucuronidation of N-glucuronides in humans is still unknown and remains to be determined.

The modulatory potential of transporter inhibitors (MK-571 and Ko143) on UGT2B10 activity was determined using the glucuronidation/glucosidation assays (Fig. 7). This type of experiment was necessary to unbiasedly interpret the effects of transporters on cellular metabolism. Our previous study has shown that MK-571 and Ko143 significantly altered the activity of UGT1A1 enzyme (Quan et al., 2015). In this study, we found that Ko143 had an inhibitory effect on $\mathrm{N}$-glucuronidation of mianserin and cyclizine (Fig. 7). Hence, the reduction in total $\mathrm{N}$-glucuronidation of these two compounds (Fig. 5) was not solely attributed to inhibition of BCRP. Inhibited enzyme activity may also play a role in reducing cellular $\mathrm{N}$-glucuronidation; however, since the intracellular glucuronide level is significantly elevated, an important role of BCRP in N-glucuronide transport was conclusive based on the chemical inhibition experiments (Fig. 5) (Quan et al., 2015) and was further evidenced by the biologic inhibition results (Fig. 8).
In summary, UGT2B10 catalyzed N-glucuronidation and $\mathrm{N}$-glucosidation of mianserin and cyclizine, generating both $\mathrm{N}$-glucuronides and $\mathrm{N}$-glucosides in HEK2B10 cells. The specific role of UGT2B10 in N-glucosidation was confirmed in reaction phenotyping with recombinant UGT enzymes. By using both chemical and biologic inhibition methods, we demonstrated that BCRP was primarily responsible for excretion of $\mathrm{N}$-glucosides, whereas both BCRP and MRP4 were actively involved in excretion of N-glucuronides.

\section{Authorship Contributions}

Participated in research design: Lu, Dong, Wu.

Conducted experiments: Lu, Dong, Xie.

Contributed new reagents or analytic tools: Li.

Performed data analysis: Lu, Dong, Xie, Wu.

Wrote or contributed to the writing of the manuscript: $\mathrm{Lu}, \mathrm{Wu}$.

\section{References}

Adachi Y, Suzuki H, Schinkel AH, and Sugiyama Y (2005) Role of breast cancer resistance protein (Bcrp1/Abcg2) in the extrusion of glucuronide and sulfate conjugates from enterocytes to intestinal lumen. Mol Pharmacol 67:923-928.

Barrington RD, Needs PW, Williamson G, and Kroon PA (2015) MK571 inhibits phase-2 conjugation of flavonols by Caco-2/TC7 cells, but does not specifically inhibit their apical efflux. Biochem Pharmacol 95:193-200.

Buchheit D, Dragan CA, Schmitt EI, and Bureik M (2011) Production of ibuprofen acyl glucosides by human UGT2B7. Drug Metab Dispos 39:2174-2181.

Chau N, Elliot DJ, Lewis BC, Burns K, Johnston MR, Mackenzie PI, and Miners JO (2014) Morphine glucuronidation and glucosidation represent complementary metabolic pathways that are both catalyzed by UDP-glucuronosyltransferase 2B7: kinetic, inhibition, and molecular modeling studies. J Pharmacol Exp Ther 349:126-137.

Fevery J, Van de Vijver M, Michiels R, and Heirwegh KP (1977) Comparison in different species of biliary bilirubin-IX alpha conjugates with the activities of hepatic and renal bilirubin-IX alphauridine diphosphate glycosyltransferases. Biochem J 164:737-746.

$\mathrm{Hu}$ M, Chen J, and Lin H (2003) Metabolism of flavonoids via enteric recycling: mechanistic studies of disposition of apigenin in the Caco-2 cell culture model. J Pharmacol Exp Ther 307: 314-321.

Iddon L, Bragg RA, Harding JR, Pidathala C, Bacsa J, Kirby AJ, and Stachulski AV (2009) Syntheses and structures of anomeric quaternary ammonium beta-glucosides and comments on the anomeric C-N bond lengths. Tetrahedron 65:6396-6402.

Kaivosaari S, Finel M, and Koskinen M (2011) N-glucuronidation of drugs and other xenobiotics by human and animal UDP-glucuronosyltransferases. Xenobiotica 41:652-669.

Kanoh H, Tada M, Ikushiro S, and Mohri K (2011) Characterization of bucolome N-glucuronide formation: tissue specificity and identification of rat UDP-glucuronosyltransferase isoform (s). Pharmacol Pharm 02:151-158.

Kerdpin O, Mackenzie PI, Bowalgaha K, Finel M, and Miners JO (2009) Influence of $\mathrm{N}$-terminal domain histidine and proline residues on the substrate selectivities of human UDP-glucuronosyltransferase 1A1, 1A6, 1A9, 2B7, and 2B10. Drug Metab Dispos 37: 1948-1955.

Kowalczyk I, Hawes EM, and McKay G (2000) Stability and enzymatic hydrolysis of quaternary ammonium-linked glucuronide metabolites of drugs with an aliphatic tertiary amine-implications for analysis. J Pharm Biomed Anal 22:803-811.

Li W, Sun H, Zhang X, Wang H, and Wu B (2015) Efflux transport of chrysin and apigenin sulfates in HEK293 cells overexpressing SULT1A3: The role of multidrug resistance-associated protein 4 (MRP4/ABCC4). Biochem Pharmacol 98:203-214.

Lu D, Ma Z, Zhang T, Zhang X, and Wu B (2016) Metabolism of the anthelmintic drug niclosamide by cytochrome P450 enzymes and UDP-glucuronosyltransferases: metabolite elucidation and main contributions from CYP1A2 and UGT1A1. Xenobiotica 46:1-13.

Lu D, Wang S, Xie Q, Guo L, and Wu B (2017a) Transcriptional regulation of human UDPglucuronosyltransferase $2 \mathrm{~B} 10$ by farnesoid X receptor in human hepatoma HepG2 cells. Mol Pharm 14:2899-2907.

Lu D, Xie Q, and Wu B (2017b) N-glucuronidation catalyzed by UGT1A4 and UGT2B10 in human liver microsomes: assay optimization and substrate identification. J Pharm Biomed Anal 145:692-703.

Mackenzie P, Little JM, and Radominska-Pandya A (2003) Glucosidation of hyodeoxycholic acid by UDP-glucuronosyltransferase 2B7. Biochem Pharmacol 65:417-421.

MacKenzie PI, Rogers A, Elliot DJ, Chau N, Hulin JA, Miners JO, and Meech R (2011) The novel UDP glycosyltransferase 3A2: cloning, catalytic properties, and tissue distribution. Mol Pharmacol 79:472-478.

Mackenzie PI, Rogers A, Treloar J, Jorgensen BR, Miners JO, and Meech R (2008) Identification of UDP glycosyltransferase $3 \mathrm{~A} 1$ as a UDP N-acetylglucosaminyltransferase. J Biol Chem 283: 36205-36210.

Mastrianni KR, Lee LA, Brewer WE, Dongari N, Barna M, and Morgan SL (2016) Variations in enzymatic hydrolysis efficiencies for amitriptyline and cyclobenzaprine in urine. J Anal Toxicol 40:732-737.

Meech R, Miners JO, Lewis BC, and Mackenzie PI (2012) The glycosidation of xenobiotics and endogenous compounds: versatility and redundancy in the UDP glycosyltransferase superfamily. Pharmacol Ther 134:200-218.

Meech R, Mubarokah N, Shivasami A, Rogers A, Nair PC, Hu DG, McKinnon RA, and Mackenzie PI (2015) A novel function for UDP glycosyltransferase 8: galactosidation of bile acids. Mol Pharmacol 87:442-450.

Neighbors SM and Soine WH (1995) Identification of phenobarbital N-glucuronides as urinary metabolites of phenobarbital in mice. Drug Metab Dispos 23:548-552. 
Patana AS, Kurkela M, Finel M, and Goldman A (2008) Mutation analysis in UGT1A9 suggests a relationship between substrate and catalytic residues in UDP-glucuronosyltransferases. Protein Eng Des Sel 21:537-543.

Quan E, Wang H, Dong D, Zhang X, and Wu B (2015) Characterization of chrysin glucuronidation in UGT1A1-overexpressing HeLa cells: elucidating the transporters responsible for efflux of glucuronide. Drug Metab Dispos 43:433-443.

Radominska-Pandya A, Bratton SM, Redinbo MR, and Miley MJ (2010) The crystal structure of human UDP-glucuronosyltransferase 2B7 C-terminal end is the first mammalian UGT target to be revealed: the significance for human UGTs from both the 1A and 2B families. Drug Metab Rev 42:133-144.

Rowland A, Miners JO, and Mackenzie PI (2013) The UDP-glucuronosyltransferases: their role in drug metabolism and detoxification. Int J Biochem Cell Biol 45:1121-1132.

Sesink AL, Arts IC, de Boer VC, Breedveld P, Schellens JH, Hollman PC, and Russel FG (2005) Breast cancer resistance protein (Bcrp1/Abcg2) limits net intestinal uptake of quercetin in rats by facilitating apical efflux of glucuronides. Mol Pharmacol 67:1999-2006.

Sun H, Wang X, Zhou X, Lu D, Ma Z, and Wu B (2015a) Multidrug resistance-associated protein 4 (MRP4/ABCC4) controls efflux transport of hesperetin sulfates in sulfotransferase 1A3overexpressing human embryonic kidney 293 cells. Drug Metab Dispos 43:1430-1440.

Sun H, Zhou X, Zhang X, and Wu B (2015b) Decreased expression of multidrug resistanceassociated protein 4 (MRP4/ABCC4) leads to reduced glucuronidation of flavonoids in UGT1A1-overexpressing HeLa cells: the role of futile recycling. J Agric Food Chem 63 6001-6008.

Wang S, Xing H, Zhao M, Lu D, Li Z, Dong D, and Wu B (2016) Recent advances in understanding of kinetic interplay between phase II metabolism and efflux transport. Curr Drug Metab 17:922-929.
Wu B, Kulkarni K, Basu S, Zhang S, and Hu M (2011) First-pass metabolism via UDPglucuronosyltransferase: a barrier to oral bioavailability of phenolics. J Pharm Sci 100: 3655-3681.

Xu H, Kulkarni KH, Singh R, Yang Z, Wang SW, Tam VH, and Hu M (2009) Disposition of naringenin via glucuronidation pathway is affected by compensating efflux transporters of hydrophilic glucuronides. Mol Pharm 6:1703-1715.

Yang Z, Zhu W, Gao S, Yin T, Jiang W, and Hu M (2012) Breast cancer resistance protein (ABCG2) determines distribution of genistein phase II metabolites: reevaluation of the roles of ABCG2 in the disposition of genistein. Drug Metab Dispos 40:1883-1893.

Zhang X, Dong D, Wang H, Ma Z, Wang Y, and Wu B (2015) Stable knock-down of efflux transporters leads to reduced glucuronidation in UGT1A1-overexpressing HeLa cells: the evidence for glucuronidation-transport interplay. Mol Pharm 12:1268-1278.

Zhao M, Wang S, Li F, Dong D, and Wu B (2016) Arylsulfatase B mediates the sulfonationtransport interplay in human embryonic kidney 293 cells overexpressing sulfotransferase $1 \mathrm{~A} 3$. Drug Metab Dispos 44:1441-1449.

Zhou D, Guo J, Linnenbach AJ, Booth-Genthe CL, and Grimm SW (2010) Role of human UGT2B10 in N-glucuronidation of tricyclic antidepressants, amitriptyline, imipramine, clomipramine, and trimipramine. Drug Metab Dispos 38:863-870.

Address correspondence to: Dr. Baojian Wu, College of Pharmacy, Jinan University, 601 Huangpu Avenue West, Guangzhou 510632, China. E-mail: bj.wu@ hotmail.com 